\title{
Percutaneous transgastric endoscopic myotomy for upper esophageal spastic stricture
}

Various studies have reported the safety and efficacy of peroral endoscopic myotomy (POEM) for the treatment of esophageal motility spastic disorders, including type III esophageal achalasia, jackhammer esophagus, and distal esophageal spasm [1 - 3]. Moreover, there is increasing evidence that the efficacy of POEM for the treatment of nonachalasia esophageal spastic diseases is comparable to laparoscopic Heller myotomy [4, 5]. However, the application of POEM for the treatment of upper esophageal spasm located close to the esophageal introitus is limited, because the POEM procedure involves mucosal incision and submucoal tunneling usually starting at over $5 \mathrm{~cm}$ from the oral side of the spastic segment.
Here, we describe the case of a patient with upper esophageal spastic stricture, which was successfully treated with percutaneous transgastric endoscopic myotomy (PTEM), a new approach enabling submucoal tunneling myotomy from the anal side of the stricture.

A 46-year-old woman presented with a 3-year history of recurrent odynophagia and dysphagia. As a result of the longterm hypoalimentation, the patient was very severely underweight, with a body mass index of $14 \mathrm{~kg} / \mathrm{m}^{2}$. Barium esophagogram and high resolution manometry showed upper esophageal spastic stricture from the esophageal introitus, which a regular gastroscope could not traverse. PTEM was then performed for the treatment of this patient ( $\vee$ Video 1 ). A gastroscope was used to access the gastral cavity percutaneously through the abdominal wall. The gastroscope subsequently passed through the cardia into the esophageal lumen to reach the stricture segment ( $\triangleright$ Fig.1a,b). After submucosal injection, a mucosal incision was made at $5 \mathrm{~cm}$ from the anal side of the stricture segment. A submucosal tunnel was created and progressed over the cricopharyngeal muscle by $0.5 \mathrm{~cm}$ ( $\vee$ Fig. 1 c). Full-thickness myotomy was performed from $1 \mathrm{~cm}$ below the mucosal incision up to the end of the submucosal tunnel ( $\triangleright$ Fig.1d). Metallic clips were used to close the mucosal incision site
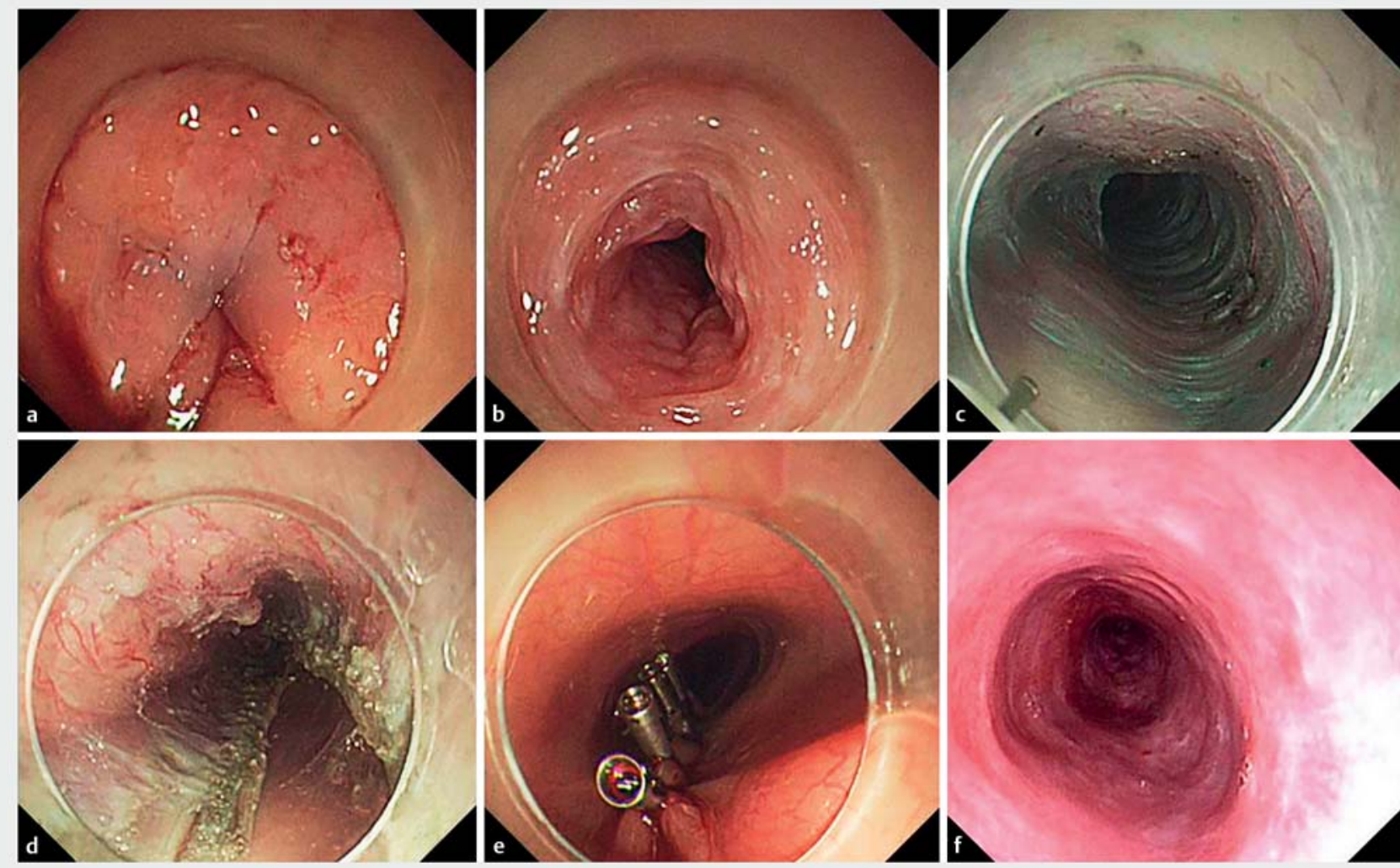

- Fig. 1 Endoscopic views. a The gastroscope traversing the cardia retrogradely. b The anal side of the stricture segment. c Submucosal tunneling. d Myotomy. e Closure of the mucosal incision. $\mathbf{f}$ Upper esophageal lumen at follow-up. 


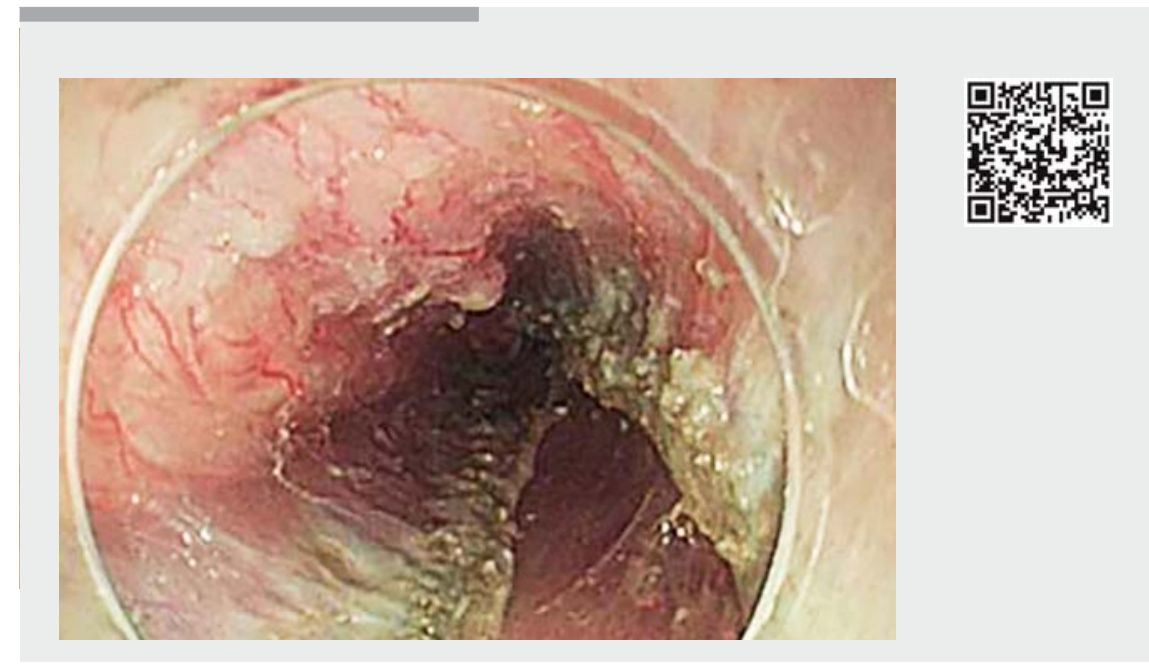

Video 1 The procedure of percutaneous transgastric endoscopic myotomy.

after careful hemostasis ( $\triangleright$ Fig. 1 e). The patient's symptoms resolved and a normal diet was resumed 2 weeks after PTEM.

At follow-up, barium esophagogram showed that the stricture of the upper esophagus was markedly improved, and a regular gastroscope was able to pass through the upper esophageal lumen (• Fig.1f).

Endoscopy_UCTN_Code_TTT_1AO_2AN

\section{Acknowledgments}

This work was supported by National Natural Science Foundation of China (81000887), Science and Technology Planning Project of Guangdong Province (2016A020215041), and the Junior Teacher Cultivation Project of Sun Yat-sen University (15ykpy18).
Competing interests

None

The authors

Xiang-bin Xing*, Yi Cui", Zhen-zi Huang, Yao He, Ying-lian Xiao, Zhi-rong Zeng, Min-hu Chen

Department of Gastroenterology, the First Affiliated Hospital of Sun Yat-sen University, Guangzhou, China

\section{Corresponding author}

\section{Min-hu Chen, MD}

Department of Gastroenterology, the First Affiliated Hospital of Sun Yat-sen University, 58 Zhongshan II Road, 510080 Guangzhou, China

Fax: +86-20-87332916

chenminhu@mail.sysu.edu.cn

* These authors contributed equally to this work.

\section{References}

[1] Dawod E, Saumoy M, Xu MM et al. Peroral endoscopic myotomy (POEM) in jackhammer esophagus: a trick of the trade. Endoscopy 2017; 49: E254-E255

[2] Bechara R, Ikeda H, Inoue H. Peroral endoscopic myotomy for Jackhammer esophagus: to cut or not to cut the lower esophageal sphincter. Endosc Int Open 2016; 4: E585-E588

[3] Khan MA, Kumbhari V, Ngamruengphong S et al. Is POEM the answer for management of spastic esophageal disorders? A systematic review and meta-analysis. Dig Dis Sci 2017; 62: 35-44

[4] Estremera-Arévalo F, Albéniz E, Rullán M et al. Efficacy of peroral endoscopic myotomy compared with other invasive treatment options for the different esophageal motor disorders. Rev Esp Enferm Dig 2017; 109: $578-586$

[5] Schlottmann F, Shaheen NJ, Madanick RD et al. The role of Heller myotomy and POEM for nonachalasia motility disorders. Dis Esophagus 2017; 30: $1-5$

\section{Bibliography}

DOI https://doi.org/10.1055/a-0885-9000

Published online: 7.6.2019

Endoscopy 2019; 51: E345-E346

(c) Georg Thieme Verlag KG

Stuttgart · New York

ISSN 0013-726X

\section{ENDOSCOPY E-VIDEOS \\ https://eref.thieme.de/e-videos}

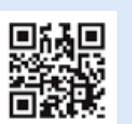

Endoscopy E-Videos is a free access online section, reporting on interesting cases and new

techniques in gastroenterological endoscopy. All papers include a high quality video and all contributions are freely accessible online.

This section has its own submission website at https://mc.manuscriptcentral.com/e-videos 